\title{
Students' Health Seeking Behaviour and its Rationale at Uganda Christian University
}

\author{
Article by Edward Kibikyo Mukooza ${ }^{1}$, Deirdre Carabine ${ }^{2}$ and Ekiria Kikule ${ }^{3}$ \\ ${ }^{1,3}$ Uganda Christian University, Uganda \\ ${ }^{2}$ Virtual University of Uganda, Uganda \\ E-mail:mukooza_edward@yahoo.com ${ }^{1,}$ d.carabine@virtualuni.ac.ug ${ }^{2}$,ekikule@ucu.ac.ug ${ }^{3}$
}

\begin{abstract}
Uganda Christian University's records of 2013-2014 show that approximately 30\% of the 3,300 students in the Easter Semester did not register for and therefore could not use the University's health services.

This study analysed Uganda Christian University students' health seeking behaviour in order to identify their preferred health care services and rationale for their choice, and the barriers to the University's health system.

A cross-sectional and mixed design was applied. Data was collected with a questionnaire administered to a sample of 424 Uganda Christian University students in April 2015. Quantitative data was analysed with SPSS 16. Qualitative data was analysed by content analysis.

Most students came from urban (51\%) or peri-urban (23.4\%) homes and had parents or guardians with post-secondary school education (80\%). Most of the students used the university's Allan Galpin Health Centre (78\%) when in need of health care but given choice, they would prefer other health facilities, especially those nearest. The most frequent reason for choice was convenience. The females perceived their state of health differently from the males ( $p$-value 0.03) and they had more unmet health needs. Barriers include unavailability of needed services, long queues, poor customer care, lack of trust in the service, waiting to see if the health problem would resolve and lack of relevant information.

The findings are similar to those from studies done in similar contexts. Key influencers of health seeking behaviour were convenience and gender. Unavailability of needed services and customer care issues were barriers to the University health services.
\end{abstract}

Keywords: Health Seeking Behaviour, Barriers, Rationale, Uganda Christian University.

\section{Introduction}

Oleja (2003:1) define health Seeking Behaviour as "any action undertaken by individuals who perceive themselves to have a health problem or to be ill for the purpose of finding an appropriate remedy". Given any community, their health seeking behaviour will affect utilisation of the health services available to them (Musoke et al., 2014). Understanding users' health seeking behaviour is essential if policy makers are to design services that are customised to the needs of the target communities such as university students. In addition, examining users' health seeking behaviour would improve access and quality of care (Afolabi et al., 2013). Researchers have documented variables affecting health seeking behaviour and these include predisposing factors such as gender, age and education; enabling factors such as income, access to health insurance and availability of health services; need factors such as the health status; and cultural factors such as religion (Babitsch, Gohl \& Lengerke, 2012).

Uganda is a low income country with a per capita income of about United States Dollars 788 (NPA, 2015). The population of Uganda is about 37 million people of which $28 \%$ are young people aged between 15 and 29 years, and only about $4.3 \%$ of the population have attained tertiary education (UBOS, 2016). In general, health services in Uganda, and particularly in hospitals and private clinics, are pro-rich rather than pro-youths to reflect the demographics of Uganda's population (Abewe, Kwesiga, Zikusooka 2012). Studies on health seeking behaviour among young people in Africa are few and yet the majority of Uganda Christian University (UCU) students are young adults aged between 19 and 25 (Otwombe et al., 2001; UBOS, 2012). Regarding health seeking behaviour of 
Ugandans in general, income and close proximity (convenience), are associated with increased utilisation of health services (Lawson, 2004). Morbidity and mortality in young people such as the UCU students have been found to have behavioural associations and is exacerbated by poorly designed health policies and failure of health service delivery systems (Blum, 2009). Thus, studies to understand the health seeking behaviours of young people in specific communities are valuable for informing policy makers in the process of designing relevant policies and health care systems.

Uganda Christian University was founded in 1997 by the Province of The Anglican Church of Uganda. The current student population at UCU main campus ranges between 3000 and 6000 during any one of the three semesters in a year. The main campus has a health facility, Allan Galpin Health Centre (AGHC), which is graded as a Health Centre level II by the Uganda Ministry of Health. In Uganda, health centres at level II provide only outpatient services. In addition to the formal UCU health care system, there are many drug shops, small private clinics, a government health centre level IV and a Private-Not-For-Profit (PNFP) hospital located near the University. There are also informal providers of health services who are consulted by many Ugandans including university students before the formal health care providers are consulted (Konde-Lule et al.,2006).

According to the 2013-2014 records at the UCU Data Centre and at Allan Galpin Health Centre, approximately $20-30 \%$ of Uganda Christian University students, despite fulfilling all the requirements for registration as UCU students, did not register to use the University's health services. In addition, all the students who missed the regular university examinations as a result of sickness and sought aegrotat in the year 2013-2014, presented medical forms from other health facilities.

It was not known why up to $30 \%$ of the students had not registered to use the university health services and the students' health seeking behaviour had not been systematically studied. The purpose of this study was to provide objective health-seeking-behaviour information to inform improvement of the UCU and similar health systems for better utilisation. The objectives of this study were to identify the health services used by the students of Uganda Christian University; to identify the factors that influence choice of health services used by the students at Uganda Christian University and to identify the barriers to utilizing the University's health system by the students of Uganda Christian University.

\section{Methods}

This was a cross-sectional mixed design study. Uganda Christian University has five campuses which include the main campus at Mukono, Kampala campus in Kampala city, Arua campus to the north and University Colleges at Kabale to the south west and Mbale to the east. This study was limited to students at the main campus in Mukono. This is where the biggest population of UCU students are, and where a more comprehensive health system consisting of a health centre level two with a referral system to tertiary health facilities in Kampala. Each of the other campuses has a clinic but these are not integrated with the health system at the main campus.

The population under study was students in all programs at the main campus of Uganda Christian University in the January Semester to April 2015 also known as The Easter Semester. The total number of students varies per semester but UCU has a modern data centre where students' records are captured according to gender, age, program and other variables. The total number of continuing students registered with UCU data centre for the Easter Semester (January to April 2015) was 3,300. New students were not included in the study.

\section{Sample size determination}

A representative sample to enable generalisation of findings was selected using probability sampling. For the sample size, the following statistical considerations were made:

i- Confidence of $95 \%$, ii- Margin of error of 5\%. This was the acceptable level of risk (Naing, Winn \& Rusli, 2006)

iii- $\quad$ Population proportion of 0.5 which gave the largest sample. It was applied since the actual proportion of the UCU students possessing variables of interest was unknown (Lwanga \& Lemeshow, 1991).

Using the following formula by Daniel 1999 (Naing, Winn \& Rusli, 2006) 


$$
n=\frac{Z^{2} P(1-P)}{d^{2}}
$$

a sample of 424 students was calculated as follows:

$\mathrm{n}=$ Sample size

$Z=$ For the level of confidence of $95 \%$, by convention $Z$ value is 1.96

$P=$ is the population proportion possessing variables of interest which in this case was 0.5 since the actual proportion was unknown.

$d=$ is the margin of error which in this case was 0.05 (Lwanga \& Lemeshow 1991). Using the above statistical considerations and formula, a sample of 384 was calculated and $10 \%$ added to cater for the possibility of non-response or poorly filled questionnaires. Thus, a sample of 424 students was targeted in this study.

\section{Sampling procedure}

\section{Inclusion criteria}

The program duration at Uganda Christian University ranged from 3 years (six semesters) to four years (eight semesters). Students in the $2^{\text {nd }}$ to $8^{\text {th }}$ semesters at the university, and who were registered with the data centre in the Easter Semester of January to April 2015, were included in the sample. Students from the $2^{\text {nd }}$ semester onwards were expected to have been exposed to the UCU health system and it was assumed that they had objective experiences to share in this research.

\section{Sampling}

Stratified sampling was done to improve representation. A record of all the UCU registered students meeting the selection criteria was obtained from the UCU Data Centre at Mukono. The records of students in the sampling frame from the data centre were according to the programs offered. In each program, students were stratified according to gender; and thereafter, systematic sampling was applied after working out an appropriate sampling interval in each of the programs according to the proportion of students in it. Gender stratification was done to ensure accurate representation because gender is known to influence health seeking behaviour (Rahman, 2016). The sample aimed at a ratio of 52:48 female to male to reflect the distribution of sex among UCU students.

\section{Data collection techniques}

\section{Questionnaire as the tool for data collection}

A structured pre-tested questionnaire with content adapted from other similar published studies was used (Boltena et al., 2012). It was a self-administered questionnaire where most questions were closed. Some open-ended questions were also included to enable qualitative data collection. ${ }^{19}$

\section{Data collection}

Selected students who consented to participate in the study were contacted by mobile telephone and a hard copy of the questionnaire delivered by hand to them at an agreed time convenient to the student. The filled questionnaires were checked for completeness and then filed until the time of analysis.

\section{Data analysis}

Quantitative data from the questionnaires were entered into SPSS version 16.0 for Windows. Categorical variables were summarized into frequencies and percentages. Cross tabulation of some key variables was done and findings displayed with contingency tables. To detect differences, pvalues from Pearson Chi-Square tests were used. The qualitative data in the questionnaires was analysed by manual content analysis and presented descriptively. 
DOI: 10.21522/TIJPH.2013.06.03.Art019

ISSN: $2520-3134$

\section{Ethical consideration}

To ensure protection of respondents, the protocol for the study was reviewed and approved by the Uganda Christian University Ethics Committee before data collection. Confidentiality was ensured by use of self-administered questionnaires which did not capture names of respondents.

\section{Results}

\section{Response rate}

During data collection, a sample of 424 students was targeted and an equivalent number of questionnaires were delivered by hand to the selected students. Approximately 350 questionnaires were returned and of these, after cleaning and preparation for analysis, 320 questionnaires were found usable giving a response rate of about $76 \%$.

\section{Demographics of respondents}

These are presented in table 1 . The majority of respondents were either residing off campus in private hostels, homes or renting rooms (52\%). Only $48 \%$ of the respondents resided on campus or in hostels outside campus but affiliated to UCU (privately owned but jointly managed by university administration and the owners). Fifty-eight per cent of respondents were female with the majority aged 20-25 years. Majority of respondents had urban (51\%) or peri-urban $(23.4 \%)$ areas of origin. The predominant academic discipline was social sciences $(46.6 \%)$ and the commonest religion in the sample was Christianity (92.0\%) with the Anglicans being the majority denomination (53.8\%).

\section{Highest formal education attained by household heads}

The majority of respondents $(80 \%)$ came from households where the head had post-secondary education.

\section{Respondents self-perceived health}

Table 3 shows the findings on respondents self-perceived health where the majority of the participants perceived their health as either good or excellent $(86 \%)$. However, there is a difference between the male and female respondents regarding their self-perception of health. The male respondents $(11 \%)$ rated their health as either fair or poor compared to $15 \%$ of the females. Additionally, $51 \%$ of the male rated their health as either very good or excellent whereas only $42 \%$ of the female did so. The female respondents perceived their state of health differently from the male ( $p$ $=0.026$ ).

\section{Cross-tabulation of sex by previous need for medical attention}

The data in table 4 shows that the previous need for medical attention was significantly higher among the female (79\% and p-value of 0.016$)$ than the male $(67 \%)$. Previous medical need in this study meant there was 'need for medical attention in the previous or current semesters in reference to the time of study'.

The most frequent medical attention needed was a combination of medical examination and treatment of the diagnosed condition.

\section{Cross-tabulation of health facility visited by respondents who needed medical attention and respondents' residential status}

The majority of respondents, 185(78\%), who needed medical attention visited Allan Galpin Health Centre (The University's health facility). The students residing away from campus were more likely to use 'other' health facilities than the students residing on campus ( $\mathrm{p}$-value $=0.041$ ) as communicated in table 6 .

Distribution of respondents by 'who visited and received medical attention' vs 'who visited and did not receive' medical attention and reasons for not receiving medical attention $(\mathbf{n}=185)$ 
About $29 \%$ of the respondents who visited Allan Galpin Health Centre did not receive any medical attention for the reasons summarised in table 8.

The most frequent reason for not receiving medical attention was the unavailability of the needed service (25\%) at AGHC. However, long lines (23\%), unkind health workers $(19 \%)$ and lack of trust in the university health services $(16 \%)$ were other important factors contributing to failure to access the needed medical service.

\section{Unmet medical care needs and rationale}

Data showed that $84(26 \%)$ respondents had unmet medical needs and the most frequently mentioned reasons for the unmet need were:

i- Waiting for the problem to go on its own (29\% of total responses)

ii- Unavailability of the needed service (21\% of responses)

iii- Very long line at AGHC (16\% of the responses)

iv- Lack of orientation on how to register with AGHC (8\%) and lack of trust in the AGHC services $(6 \%)$

\section{Who decides where respondents go for medical care?}

The majority of students $(82 \%)$ in the study decided where to go when in need of medical attention. When the decision of where to go for medical care was made by either the guardian/parent or friends or the family doctor, the female students (table 10) were significantly more influenced ( $\mathrm{p}$-value $=0.001$ ).

\section{Distribution of reasons and preferred choice for source of medical examination or treatment}

Allan Galpin Health Centre was the preferred choice of medical treatment or examination for $47 \%$ of the respondents. The majority of respondents $(53 \%)$ preferred other sources of health care with the leading 'other' source being the nearest health facility (30\%).

Findings in table 12 suggest that the most frequent reason for the first choice of health care source is convenience or easy access. This was the main reason among those who chose drug shop, AGHC and nearest health facility as their first choice. Other important reasons included the possibility of referral and a sense of entitlement (AGHC) as well as friendly services and private health insurance availability (where parents/guardians go).

\section{Quality of information received by participants at orientation about UCU health services}

In the sample, 224 respondents received information about UCU health services at orientation. Of the 224 , only $58.1 \%$ received sufficient information to guide them in accessing health services. For the rest of the participants in this study, no information was received or what was received was not enough to guide in decision-making.

The most frequently mentioned information which was provided at orientation included emphasis on registration after which students could then access free treatment. Information on services provided at AGHC as well as emergency numbers to call in case of need of Ambulance was available too.

\section{Discussion}

\section{Response rate}

The response rate in this study was $76 \%$. This response rate does not deviate much from what other researchers have found in studies at the individual level and from the suggested norm of $60+/-20 \%$ (Baruch, 1999). However, non-response is known to introduce bias in the findings and it may cause loss of power to detect effects because of the reduction in the sample size (Isaac et al., 2015).

\section{Demographics of respondents}

The age distribution was similar to the official age range for university students in Uganda. ${ }^{9}$ There was, however, some variation regarding distribution by gender where the ratio of female to male was found to be 59:41 and yet in the UCU data centre, it is about 52:48. The sampling targeted a ratio of 52:48 (F: M) to reflect the sex distribution of students as in the data centre but the findings show that 
more females than males responded. This might be due to the typical model of masculinity which assumes that men have little interest in their health, so may not be as interested as women in a survey like this one (Bogle, 2013). The majority of participants were Christians (92.9\%) and religion is said to affect health seeking by regulating behaviour and lifestyle choices in general (Babitsch, Gohl \& Lengerke, 2012; Aldwin et al.,2014). Christians, for example, are not expected to use the services of diviners and they are expected to pray when feeling unwell which can cause delay in seeking health care. It is possible that some of the respondents who 'waited for the problem to go on its own' (table 9), were praying. Other than distribution of sex in the sample, demographics of the participants are similar to the typical UCU student, and therefore, based on this variable, the findings may be generalised to the UCU student population.

\section{Education level of household heads at the home of participants}

The distribution of household heads is very different from that of a typical male or female Ugandans where official statistics show that only $4.3 \%$ Ugandan adults have post-secondary school education (UBOS 2016). In this study, $80 \%$ of household heads had post-secondary school education. This finding was similar to a study done at Mbarara University of Science and Technology (MUST) in 2012 where $74.6 \%$ of the students came from families headed by a person with post-secondary school education (Boltena et al.,2012). High education of household heads might be explained by the fact that UCU is a private-not-for-profit university where parents/guardians meet the full cost, and therefore, it is largely those with reasonable means of income who sponsor students to this university. In addition, it is reasonable to expect parents with high education to try their best to enable their children to attain university education. Education is said to be associated with health seeking behaviour in Uganda and it is reasonable to assume that the parents/guardians of the participants in this study would influence the behaviour of the study participants directly or indirectly (UBOS, 2012). Indeed a number of students made statements like... "I am on insurance"; "when the parents recommend a doctor, there is comfort..."; "my parents are medical and so naturally I go to them when I am not well...". Such statements show the influence of parents on students' health seeking behaviour, which imply that behaviour modification interventions may be more effective when designed in collaboration with parents.

\section{Self-perceived health of respondents}

Self-perceived health by the male was higher than that of the female. Similar findings were reported in South Africa where the self-reported health by male adults was found to be rated higher than that of female adults in South Africa (Statistics South Africa, 2004). The study in Mbarara University of Science and Technology in 2012 also found that male students rated their health higher than female students (Boltena et al., 2012). Poor self-rated health is associated with unmet health care needs and more frequent utilisation of health services (Isaac et al., 2015). Boltena and others found that among students in Mbarara University of Science and Technology, there were more female with unmet medical care needs than the male. ${ }^{18}$ In this study, the previous need for medical attention was found to be significantly higher ( $\mathrm{p}$-value of 0.02 ) for the female $(79 \%)$ than for the male $(67 \%)$, implying that the findings in this study did not differ from what Boltena et al found among MUST students in 2012. Self-perceived health does not necessarily reflect the actual health of a person but available literature suggests that it can be used as a marker to guide in modelling of health services utilisation. A disconnect between self-perceived health and reality calls for targeted messages to reduce it and improve health outcomes.

\section{Kind of medical attention need}

The majority of participants in the sample needed either a laboratory test (12\%), medical treatment $(16 \%)$ or a combination of medical examination and treatment $(39 \%)$. This is consistent with statistics from AGHC, of the causes of morbidity which show that approximately $25 \%$ of the students who use the facility are diagnosed with malaria and about $28 \%$ are diagnosed with respiratory tract infections which require both examination and treatment with medical products. This is not different from statistics from the Uganda Ministry of Health where malaria and respiratory tract infections account 
for about $60 \%$ of morbidity seen in the outpatients departments of public health facilities in Uganda (UBOS, 2016). With the right interventions, these conditions are preventable, implying that disease prevention and health promotion activities would be of value.

\section{Residential status of participants and health facility visited when in need of medical care}

The majority of students who needed medical care (78\%) used AGHC but statistical analysis comparing the student residential status and the health facility visited suggested that there was an association between these two variables with the students on campus more likely to use AGHC and the students off campus more likely to use other health facilities. These results are consistent with reasons given for the preference of medical care source. The students in this sample gave convenience as the most frequent reason for selecting the preferred source of medical care when they are in need. If one of the variables that affect convenience is assumed to be the distance to the nearest health care source, then the findings from this survey are consistent with published literature where it was found that distance travelled to the nearest health facility was an important determinant of health seeking behaviour in Uganda (Lawson, 2004). Convenient location was also cited in literature as the most frequent reason for choice of provider among rural communities in Uganda (Konde-Lule, 2006). Many students said that they used AGHC because it was convenient and those who used other health facilities, the majority cited convenience as the major reason. AGHC was also used because it was seen as a pre-paid service with many students making statements like "it has already been paid for" or that "it is a free service" or that "this is the official recommended facility". Therefore, to improve utilisation, convenience should be factored in during the development of health systems.

\section{Reasons for not receiving services from AGHC}

Approximately $29 \%$ of the students who visited AGHC did not receive service and the main reasons cited being absence of the needed service, long lines and poor customer care as well as lack of trust in the services including inability to access relevant information about how to register. Literature asserts that attitudes of medical staff negatively affect access to medical care services in Uganda (Boltena, 2012; Afolabi et al., 2013; Konde-Lule, 2006)).

\section{Reasons and proportion of students with unmet health care need in general}

In terms of the proportion of students with unmet medical needs, a similar study found a larger proportion (40\%) in comparison to $26 \%$ in this study, and students from the rural area tended to face more barriers to access health services (Boltena et al., 2012). The proportion of the sample of students with rural as their area of origin in the study at MUST was $43.7 \%$ and yet in this study, the proportion of students from rural background was only about $25 \%$ (table 1). This difference in demographic characteristics of students at UCU (fewer students with rural origin) might partly explain the lower proportion of students with unmet medical care needs (Boltena et al., 2012). It was also found in this study, that majority of students $(80 \%)$ came from homes headed by people with post-secondary school education which is also said to affect access positively (Boltena et al., 2012). Regarding the reasons for unmet medical care needs, Boltena and others found acceptability (personal attitude towards illness, health care providers and health care system) as the major barrier and findings from this study are not dissimilar (Boltena et al., 2012). The reasons for unmet health care needs require investment by the university to improve the comprehensives of the services provided to reduce referrals, cut costs and improve convenience.

\section{Who decides where students go for medical care?}

The majority of students in this study (82\%) decided where to go when in need of medical care and this is not surprising because, in general, need for autonomy defines youth and the majority of participants in this study (78\%) were below 25 years of age (UNESCO, 2016). On the other hand, consulting with friends and parents could also happen because youths tend to seek for help from people who are close to them more often than they contact the formal health system (Ssewanyana et al., 2004). Girls may be more influenced than boys as the case was in this study where females were 
significantly more influenced than males with a p-value of 0.001 (Mackian, 2003). Since the majority make decisions regarding where to go, it may be useful to intensify efforts to provide young people in educational institutions with relevant health information so that they make informed choices regarding their health seeking behaviour.

\section{Reasons and first choice for source of medical examination or treatment among respondents}

When given an opportunity to choose, majority of the participants in this study (53\%) would go to other health care facilities, other than the university health facility. Bearing in mind that for many students in the sample, the most frequent reason for their preferred choice of health care source was convenience (table 12), and that most students resided off campus (about 52\%), it is not surprising that the majority preferred other sources especially the nearest health facility $(30 \%)$.

Preference of nearest health facility is consistent with what other researchers found, where the probability of seeking formal health care in Uganda, decreased with distance (Afolabi et al., 2013; Konde-Lule). Students made statements like "the nearest health facility gives results in a short time" or "when I am off campus and I am badly off, the nearest health facility is the solution". Such statements implied that they attached more value to convenience than other variables like out-ofpocket expense. First choice was also influenced by other reasons including the option for referral $(16 \%)$, access to private health insurance which biases them to specific health facilities $(4 \%)$ and friendliness of service providers (5.9\%) as well as the fact that services at AGHC were pre-paid (13\%). The implication of this is that since the university has resident and non-resident students, it may be worthwhile considering provision of alternative arrangements, including health insurance where students may access services from health facilities of their convenience.

\section{Information received about $U C U$ health services during the respondents' orientation in the first semester at the university}

Approximately $42 \%$ (table 13 ) of participants in the study did not receive sufficient information to guide them in decision-making regarding how to use UCU health services and yet acceptability depends on information and attitudes regarding health care services (Boltena et al., 2012). There are many variables which are associated with health seeking behaviour but information availability is one of the variables which influence an individual's health seeking behaviour (Zikusooka et al., 2014). Lack of information was one of the barriers to formal health care seeking among a university community in Nigeria (Afolabi et al., 2013). Lack of information may have contributed to the $26 \%$ of students with unmet medical needs among UCU students. This is confirmed by the type of information said to have been provided including the need to register with AGHC before accessing services; emergency numbers to call; location of AGHC and the essential services available. Such information, if not provided, would likely affect access.

\section{Recommendations by participants}

Participants in this study when asked for three important changes, they frequently recommended widening the scope of, reducing waiting time, improving customer care and increasing working space (table 15). These suggested changes were consistent with reasons put forward by the participants for failing to receive services when they visited AGHC. These recommendations call for review of the university health system with these concerns in mind.

\section{Conclusion}

The main objective of the study was to identify and describe Uganda Christian University's students' health seeking behaviour and its rationale. The findings would inform the development of accessible and quality health services which meet the needs of students in UCU and similar institutions. The majority of students at Uganda Christian University come from urban (51\%) or periurban $(23.4 \%)$ homes with heads of households who have post-secondary school education $(80 \%)$. Most students use Allan Galpin Health Centre which is Uganda Christian University main health facility and the service is prepaid. However, given choice most students would prefer other health 
facilities, especially those nearest where they reside for convenience purposes. The kind of homes from which the UCU students come, mean that some of them have access to private health insurance (4.24\%), a percentage which is higher than the national average of fewer than $1 \%$ of Ugandans who have private health insurance (Zikusooka et al., 2014). The female respondents perceived their state of health differently from the male (p-value 0.026), and they had more unmet health needs. The barriers to the UCU health services include unavailability of the needed services such as eye and dental care, long lines at AGHC, poor customer care by health workers at AGHC, lack of trust in service, waiting to see if the health problem could resolve and lack of relevant information. Findings from this study are similar to findings from other similar studies in similar contexts in Nigeria and in Uganda (Boltena et al.,2012); Zikusooka et al., 2014). This implies that universities in similar contexts could draw lessons from these findings. The lesson from this study is that convenience in terms of proximity to where the students study or reside and short waiting times as well as an appropriate service mix/scope to minimise referrals should be considered when developing health care systems for institutions similar to UCU.

\section{Limitations and recommendations for further study}

This study focussed on individual behaviour and yet some authors assert that the designs of health systems and social cultural factors do affect health seeking behaviour (Zikusooka et al., 2014) In the sample size calculation, a 10\% non-response was allowed for and therefore, a $24 \%$ none-response rate may have introduced selection bias and it may also have reduced the power to detect effects. A more comprehensive study covering the environmental factors, health systems design and individual characteristics as well as a larger sample is recommended.

\section{Recommendation}

1. The leadership at UCU, and in particular the management of the university's health system, could do a cost benefit analysis to determine whether it is better to increase comprehensiveness of services, or to refer the students for services such as eye and dental care.

2. The management of AGHC could plan to do a Workload Indicators of Staffing Need (WISN) study to determine if the current staffing level is adequate for the workload at UCU (WHO, 2010). Trainings in time management and customer care to improve efficiency, reduce the waiting time and improve users' satisfaction should be considered.

3. There is need to develop a comprehensive information booklet on how to access AGHC services. The booklet could be uploaded online and some hard copies distributed to all the new students at first registration.

4. In order to improve communication and trust between the UCU students and the health workers at AGHC, a feedback system needs to be developed between the two. This could be in form of regular exit interviews or questionnaires to capture and analyse suggestions and complaints.

5. It is advised that regular continuing medical education (CME) be maintained. Any issues requiring additional training, could be captured through exit interviews and considered in documenting training needs.

\section{Tables}

Table 1. Socio demographic characteristics of the respondents $n=320$

\begin{tabular}{|l|l|l|}
\hline Variable & Frequency & Percentage \\
\hline $\begin{array}{l}\text { Residential status of the } \\
\text { respondents }\end{array}$ & 142 & 43 \\
\hline Resident on campus & 16 & 05 \\
\hline $\begin{array}{l}\text { Resident in a hostel outside } \\
\text { campus but affiliated to UCU }\end{array}$ & 114 & 35 \\
\hline $\begin{array}{l}\text { Resident in a hostel outside } \\
\text { campus and not affiliated to UCU }\end{array}$ & 20 & 06 \\
\hline Residing at home & 6 & 02 \\
\hline Live with a relative & & \\
\hline
\end{tabular}


DOI: 10.21522 /TIJPH.2013.06.03.Art019

ISSN: $2520-3134$

\begin{tabular}{|l|l|l|}
\hline Variable & Frequency & Percentage \\
\hline Renting a room & 32 & 09 \\
\hline Total & 320 & 100 \\
\hline $\begin{array}{l}\text { Sex distribution of the } \\
\text { respondents }\end{array}$ & & \\
\hline Male & 132 & 41 \\
\hline Female & 188 & 59 \\
\hline Total & 320 & 100 \\
\hline $\begin{array}{l}\text { Age distribution of the } \\
\text { respondents }\end{array}$ & & \\
\hline$<20$ & 27 & 8 \\
\hline $20-25$ & 222 & 70 \\
\hline$>25$ & 71 & 22 \\
\hline Total & 320 & 100 \\
\hline Area of origin & & \\
\hline Urban & 163 & 51 \\
\hline Peri-Urban & 75 & 23.4 \\
\hline Rural & 82 & 25.6 \\
\hline Total & 320 & 100.0 \\
\hline Academic discipline & & \\
\hline Humanities & 53 & 16.6 \\
\hline Social sciences & 149 & 46.6 \\
\hline Health Sciences & 33 & 10.3 \\
\hline Science and Technology & 85 & 26.6 \\
\hline Total & 320 & 100.0 \\
\hline Religion & & \\
\hline Anglican & 172 & 53.8 \\
\hline Catholic & 79 & 24.7 \\
\hline Pentecostal & 42 & 13.1 \\
\hline Islam & 8 & 2.5 \\
\hline SDA & 4 & 1.3 \\
\hline $\begin{array}{l}\text { Other (including Latter-day Saints, } \\
\text { Jehovah's witness and the Atheists) }\end{array}$ & 15 & 4.7 \\
\hline Total & $\mathbf{3 2 0}$ & $\mathbf{1 0 0 . 0}$ \\
\hline & & \\
\hline
\end{tabular}

Table 2. Distribution of highest formal educational level attained by the head of household $n=320$

\begin{tabular}{|l|l|l|}
\hline Level of Education of house hold head & Frequency & Percentage \\
\hline No Formal Education & 11 & 3 \\
\hline Primary Level & 17 & 5 \\
\hline Senior one to senior six & 38 & 12 \\
\hline Post-Secondary Level & 254 & 80 \\
\hline Total & $\mathbf{3 2 0}$ & $\mathbf{1 0 0}$ \\
\hline
\end{tabular}

Table 3. Self perceived health of respondents by $\operatorname{sex} n=320$

\begin{tabular}{|r|l|l|l|l|l|l|l|}
\hline \multicolumn{2}{|c|}{ Self-perceived state of Health } \\
\hline \multirow{2}{|c|}{} & Excellent & Very good & Good & Fair & Poor & Total \\
\hline \multirow{2}{*}{\begin{tabular}{c}
\multirow{2}{*}{ Total } \\
\cline { 1 - 8 }
\end{tabular}} & Male & $27(20 \%)$ & $41(31 \%)$ & $50(38 \%)$ & $12(9 \%)$ & $2(2 \%)$ & $132(42 \%)$ \\
\cline { 2 - 8 } & Female & $17(9 \%)$ & $61(33 \%)$ & $80(43 \%)$ & $29(14.5 \%)$ & $1(0.5 \%)$ & $188(58 \%)$ \\
\hline
\end{tabular}


P-value 0.026

Table 4. Distribution by sex of 237 respondents with previous need for medical attention

\begin{tabular}{|c|c|c|c|c|}
\hline & \multicolumn{2}{|c|}{$\begin{array}{l}\text { Previous need for } \\
\text { medical attention }\end{array}$} & \multirow[t]{2}{*}{ Total } \\
\hline & & Yes & No & \\
\hline \multirow[t]{2}{*}{$\mathscr{\not}$} & Male & $89(67 \%)$ & $43(33 \%)$ & $132(42 \%)$ \\
\hline & Female & $148(79 \%)$ & $40(21 \%)$ & $188(58 \%)$ \\
\hline \multicolumn{2}{|l|}{ Total } & $237(74 \%)$ & $83(26 \%)$ & $320(100 \%)$ \\
\hline
\end{tabular}

p- value 0.016

Table 5. Kind of medical attention needed $n=320$

\begin{tabular}{|l|l|l|}
\hline Medical attention & Frequency & Percentage \\
\hline Medical examination & 23 & 7 \\
\hline Laboratory & 38 & 12 \\
\hline Medical treatment & 50 & 16 \\
\hline $\begin{array}{l}\text { Both medical examination } \\
\text { and treatment }\end{array}$ & 126 & 39 \\
\hline Total & 237 & 74 \\
\hline $\begin{array}{l}\text { Did not need any medical } \\
\text { attention }\end{array}$ & 83 & 26 \\
\hline Total & $\mathbf{3 2 0}$ & $\mathbf{1 0 0}$ \\
\hline
\end{tabular}

Table 6. Distribution of respondents who needed medical attention by residential status and health facility visited $n=237$

\begin{tabular}{|c|c|c|c|c|}
\hline & \multicolumn{2}{|c|}{$\begin{array}{l}\text { Health Facility Visited } \\
\text { for Medical Attention }\end{array}$} & \multirow[t]{2}{*}{ Total } \\
\hline & & Allan Galpin & Other & \\
\hline \multirow{7}{*}{ 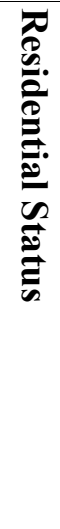 } & Resident on campus & 74 & 13 & 87 \\
\hline & $\begin{array}{l}\text { Resident in a hostel off campus } \\
\text { BUT affiliated to UCU }\end{array}$ & 9 & 5 & 14 \\
\hline & $\begin{array}{l}\text { Resident in a hostel off campus } \\
\text { and not affiliated to UCU }\end{array}$ & 74 & 18 & 92 \\
\hline & Residing at home & 8 & 8 & 16 \\
\hline & Live with a relative & 3 & 1 & 4 \\
\hline & Renting a room & 17 & 7 & 24 \\
\hline & Totals & $185(78 \%)$ & $52(22 \%)$ & $\begin{array}{l}237(10 \\
0 \%)\end{array}$ \\
\hline
\end{tabular}

Table 7. Respondents who visited AGHC and received vs did not receive the medical attention they needed

\begin{tabular}{|l|l|l|}
\hline & Frequency & Percent \\
\hline Received medical attention & 132 & 71.4 \\
\hline Did not receive medical attention & 53 & 28.6 \\
\hline Total & $\mathbf{1 8 5}$ & $\mathbf{1 0 0}$ \\
\hline
\end{tabular}


DOI: 10.21522/TIJPH.2013.06.03.Art019

ISSN: $2520-3134$

Table 8. Relative frequency distribution of reasons given by 53 respondents for not receiving treatment from AGHC. $n=53$. Multiple responses given

\begin{tabular}{|l|l|l|}
\hline $\begin{array}{l}\text { Reason for not receiving medical attention from } \\
\text { AGHC }\end{array}$ & Frequency & $\begin{array}{l}\text { Relative } \\
\text { frequency }\end{array}$ \\
\hline The service I needed is not available at AGHC & 32 & 25 \\
\hline Line at AGHC is usually too long & 29 & 23 \\
\hline The health workers are not kind & 25 & 19 \\
\hline I do not trust the university health services & 21 & 16 \\
\hline I waited to see if the problem could go by itself & 09 & 06 \\
\hline I was away from campus & 06 & 05 \\
\hline I was not registered with AGHC & 05 & 05 \\
\hline I did not have time to go for treatment & 02 & 01 \\
\hline Total responses & $\mathbf{1 2 9}$ & $\mathbf{1 0 0}$ \\
\hline
\end{tabular}

(Question: Was there any time during the previous or current semester when in your opinion, you personally needed medical attention for a health problem for which you did not go to AGHC and for which you did not receive any attention from any other service provider?)

Table 9. Frequency distribution of reasons given by 84 respondents for unmet health care need in general

\begin{tabular}{|l|c|}
\hline Reason for unmet medical need & Frequenc \\
\hline I waited for the problem to go on its own & 25 \\
\hline The service needed was not available at AGHC & 18 \\
\hline Very long line at AGHC & 14 \\
\hline I was not oriented on how to register with AGHC & 07 \\
\hline University health centre cannot be trusted & 06 \\
\hline $\begin{array}{l}\text { Medical workers at AGHC are rude and I did not want to } \\
\text { go there }\end{array}$ & 05 \\
\hline I am not registered with AGHC & 04 \\
\hline I self-treated & 04 \\
\hline $\begin{array}{l}\text { I was referred but had no money for medical examination } \\
\text { elsewhere }\end{array}$ & 03 \\
\hline Total of frequencies & $\mathbf{8 6}$ \\
\hline
\end{tabular}

Table 10. Who decides where students go for medical care vs sex? N=320

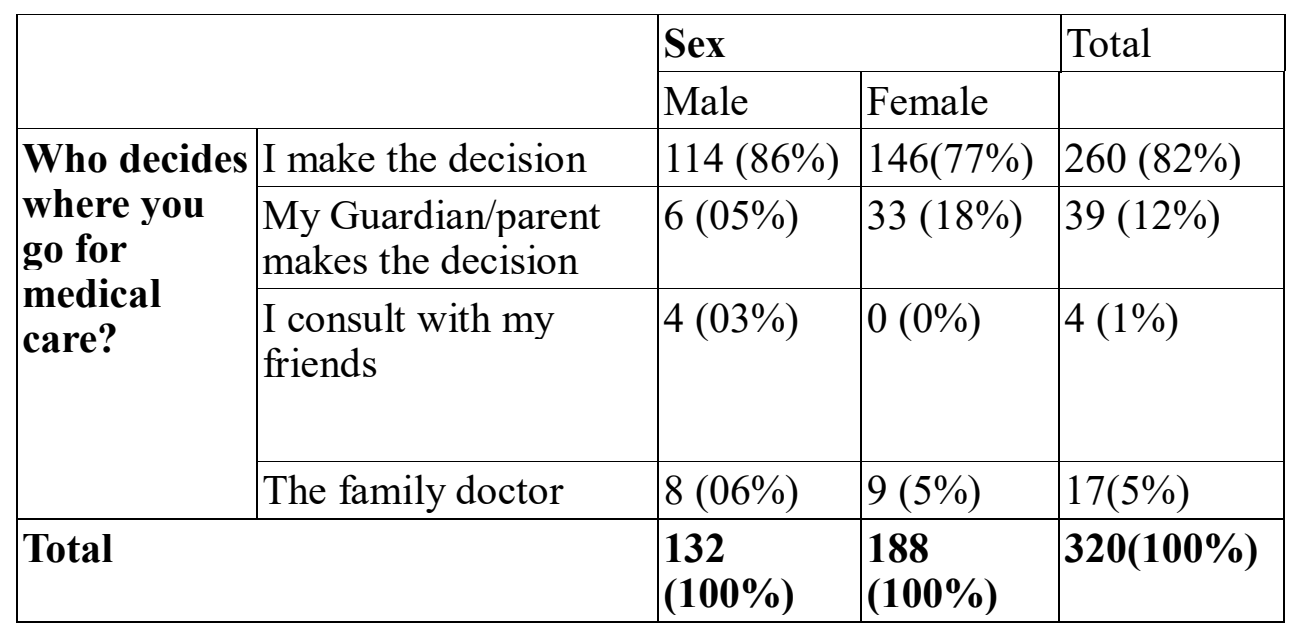

$P$-value $=0.001$ 
Table 11. First choice for source of medical examination or treatment among respondents $n=320$

\begin{tabular}{|l|l|l|}
\hline $\begin{array}{l}\text { Preferred choice for medical treatment } \\
\text { or examination }\end{array}$ & Frequency & Percentage \\
\hline Natural herb & 12 & 3.8 \\
\hline A drug shop & 19 & 5.9 \\
\hline $\begin{array}{l}\text { Allan Galpin Clinic or referral health } \\
\text { facility }\end{array}$ & 150 & 47 \\
\hline The nearest health facility & 95 & 30 \\
\hline $\begin{array}{l}\text { I would go to where my parents/guardian } \\
\text { goes when they need medical services }\end{array}$ & 44 & 14 \\
\hline Total & $\mathbf{3 2 0}$ & $\mathbf{1 0 0}$ \\
\hline
\end{tabular}

Table12. Relative frequency distribution of reasons for preference of source of medical examination or treatment $\mathrm{n}=320$. Multiple responses were given.

\begin{tabular}{|c|c|c|c|}
\hline $\begin{array}{l}\text { First choice of } \\
\text { health care } \\
\text { source }\end{array}$ & Reasons given & Frequency & $\begin{array}{l}\text { Relative } \\
\text { Frequency }\end{array}$ \\
\hline \multirow[t]{4}{*}{ Natural herbs } & Do not have side effects & 8 & $2.12 \%$ \\
\hline & It is cheap and simple & 3 & $0.80 \%$ \\
\hline & It can work as first aid & 2 & $0.50 \%$ \\
\hline & It can cure many diseases & 2 & $0.50 \%$ \\
\hline Drug shop near by & It is convenient & 16 & $4.24 \%$ \\
\hline \multirow[t]{3}{*}{ AGHC } & Easy access/convenience & 82 & $21.75 \%$ \\
\hline & They are qualified and can refer & 62 & $16.45 \%$ \\
\hline & $\begin{array}{l}\text { I paid for the service and I am entitled to it } \\
\text { (pre-paid) }\end{array}$ & 49 & $13.00 \%$ \\
\hline \multirow{5}{*}{$\begin{array}{l}\text { The nearest health } \\
\text { facility }\end{array}$} & Convenience/ease of access/time saving & 80 & $21.22 \%$ \\
\hline & $\begin{array}{l}\text { Because AGHC has disappointed me in the } \\
\text { past }\end{array}$ & 11 & $02.92 \%$ \\
\hline & Response is better & 07 & $01.9 \%$ \\
\hline & I have private health insurance & 03 & $00.80 \%$ \\
\hline & Some services not available at AGHC- & 01 & $00.26 \%$ \\
\hline \multirow{5}{*}{$\begin{array}{l}\text { Where my } \\
\text { guardian/parent } \\
\text { goes when in need } \\
\text { of health care }\end{array}$} & $\begin{array}{l}\text { They have friendly services, are thorough } \\
\text { and they know me }\end{array}$ & 22 & $5.90 \%$ \\
\hline & My family has private health insurance & 16 & $4.24 \%$ \\
\hline & $\begin{array}{l}\text { I trust services selected and used by my } \\
\text { parents }\end{array}$ & 06 & $1.59 \%$ \\
\hline & I get immediate attention & 05 & $1.33 \%$ \\
\hline & My parents are medical professionals & 02 & $0.50 \%$ \\
\hline $\begin{array}{l}\text { Total of } \\
\text { frequencies }\end{array}$ & & 377 & $100 \%$ \\
\hline
\end{tabular}

Table13. Quality of information received about UCU health services during the respondents' orientation in the first semester at the university. $n=320$

\begin{tabular}{|c|l|l|}
\hline Quality of information provided & Frequency & Percent \\
\hline $\begin{array}{c}\text { Sufficient to guide you in accessing the UCU } \\
\text { health services }\end{array}$ & 186 & 58.1 \\
\hline $\begin{array}{c}\text { Not sufficient to guide you in accessing the } \\
\text { UCU health services }\end{array}$ & 32 & 10.0 \\
\hline Not useful at all & 6 & 1.9 \\
\hline
\end{tabular}


DOI: $10.21522 /$ TIJPH.2013.06.03.Art019

ISSN: $2520-3134$

\begin{tabular}{|l|l|l|}
\hline No information received & 96 & 30.0 \\
\hline Total & 320 & 100.0 \\
\hline
\end{tabular}

Table 14. Relative frequency distribution of content of information provided at orientation. $n=224$, Multiple responses given

\begin{tabular}{|l|l|l|}
\hline Information provided & Frequency & $\begin{array}{l}\text { Relative } \\
\text { frequency }\end{array}$ \\
\hline $\begin{array}{l}\text { After registration with AGHC, students can } \\
\text { then access free treatment or referrals during } \\
\text { the semester }\end{array}$ & 96 & $35.30 \%$ \\
\hline $\begin{array}{l}\text { Information on services at AGHC and } \\
\text { ambulance/emergency numbers to call in case } \\
\text { of need }\end{array}$ & 43 & $15.81 \%$ \\
\hline Go to AGHC whenever we fell sick & 36 & $13.24 \%$ \\
\hline Location of AGHC in UCU & 35 & $12.87 \%$ \\
\hline $\begin{array}{l}\text { Information about all essential services } \\
\text { available at AGHC was provided }\end{array}$ & 20 & $7.35 \%$ \\
\hline 24 hour and first aid services were available & 16 & $5.88 \%$ \\
\hline Showed how AGHC worked & 14 & $5.15 \%$ \\
\hline Self-treatment was discouraged & 5 & $1.84 \%$ \\
\hline Told about the Health Awareness Weeks & 5 & $1.84 \%$ \\
\hline Encouraged to sleep under a mosquito net & 2 & $0.72 \%$ \\
\hline Totals & $\mathbf{2 7 2}$ & $\mathbf{1 0 0 \%}$ \\
\hline
\end{tabular}

\section{Acknowledgement}

We would like to thank the Uganda Christian University Students of the Easter Semester of 2015 from whom data was collected; the students of Bachelor of Community Health, year three of 2015, who assisted with data collection; the Uganda Christian University Ethics Committee which reviewed the protocol and granted ethical clearance. Thank you for your contributions.

\section{References}

[1].Abewe C, Kwesiga B, Zikusooka CM. Who Benefits from Health Care Services in Uganda? Sector-Wide Benefit Incidence Analysis for Uganda (2005/6 and 2009/10) .2012. Available from: http://ssrn.com/abstract=2281752 . [cited 2016 Jan $8^{\text {th }}$.

[2].Afolabi M, Daropale V, Irinoye A. and Adegoke A. Health-seeking behaviour and student perception of health care services in a university community in Nigeria. Health, 5, 817-824. 2013. [cited 2015 Jun $19^{\text {th }}$ ] doi: 10.4236/health.2013.55108.

[3].Aldwin C.M, Park C, L, Jeong Y, Nath. R. 2014. Differing pathways between religiousness, spirituality, and health: A self-regulation perspective. Psychology of Religion and Spirituality, 6 (1): 9 DOI: 10.1037/a0034416

[4].Babitsch B, Gohl D. and Lengerke T. Re-revisiting Andersen's Behavioural Model of Health Services Use: a systematic review of studies from1998- 2011. Special issue: Health care utilization in Germany: The NW In research network. 2012. Available from http://www.ncbi.nlm.nih.gov/pmc/articles/PMC3488807/pdf/PSM-0911.pdf [cited 2015 Jun $1^{\text {st }}$ ]

[5].Baruch, Y., 1999. Response Rates in Academic Studies- A Comparative Analysis Survey response rate levels and trends in organizational research. Human Relations 2008; 61; 1139. Available online at

[6]. http://journals.sagepub.com/doi/abs/10.1177/001872679905200401 [cited 2017 May $15^{\text {th }}$ ]

[7].Blum. 2009. Young People: Not as healthy as they seem. The Lancet. Vol. 374 September, 2009.

[8].Bogle V., 2013. A review of the literature: men's health-seeking behaviourand use of the internet. Available online

https://www.menshealthforum.org.uk/sites/default/files/pdf/mens_health_literature_review_dec2013_final.pdf [cited 2015 Sept $25^{\text {th }}$ ] 
[9].Boltena A.T., Ali Khan F., Benedict O. Asamoah B.O. and Agardh A., 2012. Barriers faced by Ugandan university students in seeking medical care and sexual health counselling: a cross-sectional study. Available at http://www.biomedcentral.com/1471-2458/12/986 [cited 2015 Jan. 29th]

[10]. Isaac, V., Mclachlan, C. S., Baune, B. T., Huang, C.-T., \& Wu, C.-Y. (2015). Poor Self-Rated Health Influences Hospital Service Use in Hospitalized Inpatients With Chronic Conditions in Taiwan. Medicine, 94(36), e1477. https://doi.org/10.1097/MD.0000000000001477

[11]. Konde-Lule J., Okuonzi S., Matsiko C., Mukanga D., Onama V. and Gitta S.N., 2006. The Potential of The Private Sector to Improve Health Outcomes in Uganda.

[12]. Lawson D., 2004. Determinants of Health Seeking Behaviour in Uganda -Is it Just Income and User Fees That Are Important?. Available online at https://ideas.repec.org/p/ags/idpmde/30553.html [cited 2015 January 20th]

[13]. Lwanga S.K., and Lemeshow S.,1991. Sample Size Determination In Health Studies: A practical Manual. World Health Organisation. Geneva.

[14]. Mackian S., 2003. University of Manchester Health Systems Development Programme. A review of health seeking behaviour: problems and prospects. Available at http://r4d.dfid.gov.uk/pdf/outputs/healthsysdev_kp/0503_health_seeking_behaviour.pdf [cited 2015 March 13 ${ }^{\text {th }}$ ]

[15]. Ministry Of Health (Uganda). (2015). Health Sector Strategic and Development Plan (2015-2020) From: http://health.go.ug/content/health-sector-development-plan-201516-201920 [ cited 2015 Dec. $20^{\text {th }}$ ]

[16]. Musoke D, Boynton P, Butler C, Musoke MB. Health seeking behaviour and challenges in utilising health facilities in Wakiso district, Uganda. 2014. Available from http://www.bioline.org.br/pdf?hs14155 [cited 2015 Jun $23^{\text {rd }}$.

[17]. Naing L., Winn T. and Rusli B.N., 2006. Practical Issues in Calculating Sample Sizes for Prevalence Studies. Archives of Orofacial Sciences 2006; 1:9-14. Available online at http://www.kck.usm.my/ppsg/aos/Vol_1/09_14_Ayub.pdf (cited 2015 Feb. $3^{\text {rd }}$ ]

[18]. National Planning Authority [NPA] (Uganda). Second National Development Plan (NDPII) 2015/16 2019/20. 2015. Available from: npa.ug/wp-content/uploads/NDPII-Final.pdf [cited 2015 Oct $10^{\text {th }}$ ].

[19]. Olenja J. Health Seeking Behaviour in Context. East African Medical Journal. 2003. Available from http://www.ajol.info/index.php/eamj/article/viewFile/8689/1927 [cited 2015 Jan 28th].

[20]. Otwombe K., Dietrich J., Laher F., Hornschuh S., Nkala B., Chimoyi L., Kaida A., Gray G.E., and Miller C.L., 2001. Health-seeking behaviour by gender among adolescents in Soweto, South Africa. Available online at http://www.globalhealthaction.net/index.php/gha/article/view/25670/pdf_28 [cited 2016 June 19th]

[21]. Polit, D.F., \& Beck, C.T., 2009. Nursing research: generating and assessing evidence for nursing practice. 8th edition. Philadelphia: JB Lippincott.

[22]. Rahman S. 2016. Sex, Gender and Health Seeking Behaviour Determinants. NU Journal of Humanities, Social Sciences \& Business Studies Vol. 2, No. 2, January-June 2016. Available at www.nu.edu.bd/.../01.\%20Sex,\%20Gender\%20and\%20Health\%20Seeking\%20Behav...

[23]. [cited 2016 Jan. $3^{\text {rd }}$ ]

[24]. Ssewanyana S., Nabyonga O.J., Kasirye I. \& Lawson D., 2004. Demand for health care services in Uganda Implications for poverty eradication. Economic Policy Research Center Research series No. 40, EPRC Makerere University, Kampala Uganda.

[25]. Statistics South Africa., 2004. Perceived health and other health indicators in South Africa Statistics South. Available online at www.statssa.gov.za/.../HealthOHS/HealthOHS1999.... [ cited 2015 Sept. 27 $7^{\text {th }}$ ]

[26]. UBOS., 2012. Uganda Demographic and Health Survey 2011. Uganda Bureau of Statistics Kampala, Uganda

[27]. Uganda Bureau of Statistics (UBOS). The National Population and Housing Census 2014 - Main Report, Kampala, Uganda. 2016.

[28]. Uganda Bureau of Statistics (UBOS). 2013. Statistical Abstract. Uganda Bureau of Statistics, Statistics House. Kampala.

[29]. UNESCO., 2015. What do we mean by "youth"?. Available online at http://www.unesco.org/new/en/social-and-human-sciences/themes/youth/youth-definition/ (accessed on $1^{\text {st }}$ October 2015).

[30]. WHO., 2010. Workload Indicators of Staffing Need (WISN) User's manual. Available online at http://www.who.int/hrh/resources/wisn_user_manual/en/ (accessed on 7th Oct. 2015) 
DOI: $10.21522 /$ TIJPH.2013.06.03.Art019

ISSN: $2520-3134$

[31]. Zikusooka C.M., Kwesiga B., Lagony S., and Abewe C., 2014. Universal Health Coverage Assessment Uganda. Global Network for Health Equity (GNHE). 